\title{
EXPERIMENTAL INVESTIGATION OF INFLUENCE OF PROCESS PARAMETERS ON FRICTIONAL FORCE AND SURFACE ROUGHNESS DURING MACHINING OF AL 6081 MATERIAL
}

\author{
Lokesha $^{1}$, P B Nagaraj ${ }^{2}$, P Dinesh ${ }^{3}$ \\ Department of Mechanical Engineering, M S Ramaiah Institute of Technology, Bangalore
}

\begin{abstract}
In the world of engineering manufacturing, condition of a machine tool is always an important aspect which directly relates to the productivity of the manufacturing process. The machining parameters are the most generally considered factors which influence the working condition of the machine tool. Appropriate selection of these parameters will always lead to effective management of the machine tool condition and its productivity. In the present study, an effort has been made to select appropriate machining / process parameters and study the influence of these parameters on the productivity of the machine tool, measured in terms of machined part surface roughness quality. The experimental trials were planned based on Taguchi's orthogonal array and cutting forces were measured for each trial along with the surface roughness. Frictional force between the cutting tool and work piece has been computed with the help of cutting forces and tool geometry, further a relationship between the frictional force and surface roughness has been built with the help of ANOVA.
\end{abstract}

Keywords: Process parameters, productivity, Taguchi, ANOVA

\section{INTRODUCTION}

Machine tool in a manufacturing industry is always considered to be the main tool in machining process. The existence of manufacturing industry is majorly dependent on the machine tool and its productivity. Selection of machining parameters such as cutting speed, depth of cut and feed rate are directly related to the machine tool productivity and hence it is always important to use proper combinations of these parameters while performing the machining process of late several developments have taken place in the area of machine tool and its effective utilization with the intention of better management of its productivity. Muhammad Munawar, et. al. carried out a experiment to investigate the influence of machine tool vibration on surface roughness with input variables as constant cutting speed and depth cut, along with variable feed rate and cutting tool insert nose radius. The experiment was designed using Taguchi orthogonal array and analyzed the input and output relationship with the help of Analysis of variance (ANOVA). This study provides the influence of cutting tool nose radius on surface roughness [1]. Satyanarayana Kosaraju, et. al. carried out an experimental study to determine the optimal process parameters for machining Titanium Ti-6Al-4V material using Taguchi and ANOVA techniques. The material was subjected to turning operation in a precision turning machine for different process parameters such as cutting speed, depth of cut and feed rate and cutting forces and temperature were measured as output performance characteristics. This study provided the acceptable relationship between the input and output parameters [2]. Farhad Kolahan, et. al. carried out an experimental study on AISI 1045 steel material to investigate the effect of process parameters and tool geometry on surface roughness in a turning operation and predict the optimal process parameters and tool geometry for good surface finish. Process parameters such as cutting speed, feed rate, depth of cut and cutting tool nose radius along with tool geometry parameters such as rake angle, side cutting edge angle and end cutting edge angle were considered as inputs for the experimental work. In this study, the effects of each parameter were determined [3]. They also carried out experimental work on AISI1045 steel using HSS cutting tool for process parameter optimization of machining parameters and tool geometry on lathe, illustrates that feed rate has significant effect compared to other parameters on surface roughness [4]. Zeelan Basha N, et. al. carried out an experimental study to analyze the effect of cutting parameters on surface roughness in CNC lathe using coated carbide tool for aluminum 6063 material. The regression equations were solved using genetic algorithm approach in mat lab 8.0 application. Finally this study revealed the optimum input values in order to obtain best surface finish [5]. Vikas B. Magdum, et. al., carried out an experimental work on EN 8 steel bars with high speed steel (HSS) tool on tool wear monitoring in turning revealed that the tool wear increases as cutting speed increases [6]. Harish Kumar, et. al., conducted a study on MS 1010 material in 
CNC turning operation with HSS tool type was carried out to optimize the machining parameters such as cutting speed, feed rate and depth of cut with the help of Taguchi and ANOVA techniques. This study revealed that the spindle speed plays key role in minimizing the surface roughness [7]. N. Kusuma, et. al. carried out an experimental work on a CNC milling machine to analyze the influence of cutting parameters on surface finish and machine tool vibration. The experimental work also includes the prediction of the surface roughness value and optimization of the cutting parameters. Analysis of Variance (ANOVA), Artificial Neural Network (ANN) and Genetic Algorithm (GA) were used respectively to carry out the process. ANOVA analysis were conducted for both full factorial and Taguchi experimental values and the results obtained reveals that Taguchi technique is most suitable considering time and cost of the experimental work and the analysis also reveals the influence of process parameters on vibration and surface roughness [8]. The survey review provides a platform to carry out the experimental investigations for improvising the knowledge base for the manufacturing organizations in selecting proper process parameters to enhance the productivity of the machine tool. In context with this, an effort has been made to study the influence of process parameters on the frictional force and the quality of surface finish during machining of $\mathrm{Al} 6081$ material using Taguchi and ANOVA tools.

\section{DESIGN OF EXPERIMENTS}

Design of experiments is a series of tests or experiments carried out, in which the input variables of a system or a process are purposefully varied and then their effects on the response variables are measured. Design of experiments is applicable to both physical processes and computer simulation models. DOE is an effective tool which maximizes the amount of information gained from a study while minimizing the amount of data to be collected. Factorial design and Taguchi orthogonal array are the most frequently used design of experiments method in experimental studies. [9]

Taguchi orthogonal array: As the number of factors increases, a large number of experiments have to be carried out in full factorial design which becomes laborious and complex. In order to overcome the above problem Taguchi suggested a specially designed method called the Taguchi method which makes use of orthogonal array to study the entire parameter with lesser number of experiments to be conducted. Taguchi also recommended the use of the loss function to measure the performance characteristics that are deviating from the desired target value. Finally this value of loss function is further transformed into signal-to-noise $(\mathrm{S} / \mathrm{N})$ ratio. To analyze this $(\mathrm{S} / \mathrm{N})$ ratio, there are three categories of the performance characteristics. They are: nominal-the-best, larger-the-better, and smaller-the-better. [10]

\section{ANALYSIS OF VARIANCE (ANOVA)}

The analysis of variance which is frequently referred to as ANOVA is a statistical technique which is specially designed to test whether the means of two or more quantitative populations are equal. Basically, ANOVA consists of classifying and cross classifying statistical results in which testing is carried out to check whether the means of specified classification differ significantly. In this way ANOVA is helpful in determining whether the given classification is important in affecting the results and also helps us to analyze the total variation of our data into components which may be attributed to various sources or causes of variation. ANOVA are classified into two types namely one way and two way ANOVA.

In general, one way ANOVA technique is used to study the effects of a single factor over a variety of levels. But this technique cannot be used for multi factor analysis. When two or more independent factors have an effect on response variable which is of interest, then it is possible to design the test so that analysis of variance can be used to test for the effects of two or more factors simultaneously. Such a test is called two-way analysis of variance which is made use of in the present study. The F-test in ANOVA is used to assess whether the expected values of a variable is within several pre-defined factors and levels differ from each other. Based on this F-test in ANOVA the factors affecting the output of the experiment and to amount of which these factors affect can be determined. [11]

\section{EXPERIMENTAL SETUP}

The experimental trials for the present investigation have been carried out on HMT LT20 lathe for machining a $20 \mathrm{~mm}$ diameter Al 6081 specimens. The experimental trials were designed based on Taguchi's L9 orthogonal array design of experiments technique with the selected three levels of process parameters, spindle speed, feed rate and depth of cut. The selected process parameters and respective levels have been tabulated as in the table 1 and different combinations for the experimental trials were tabulated according to the Taguchi's L9 series as in the table 2 .

Table 1: Selected Process parameters

\begin{tabular}{|l|l|l|l|}
\hline Levels & $\begin{array}{l}\text { Cutting speed } \\
\text { (RPM) }\end{array}$ & $\begin{array}{l}\text { Feed rate } \\
(\mathrm{mm} / \mathrm{rev})\end{array}$ & $\begin{array}{l}\text { Depth of cut } \\
(\mathrm{mm})\end{array}$ \\
\hline 1 & 420 & 0.05 & 0.50 \\
\hline 2 & 710 & 0.11 & 0.75 \\
\hline 3 & 1200 & 0.22 & 1.00 \\
\hline
\end{tabular}

Table 2: Number of Experimental as per Taguchi's L9 orthogonal array

\begin{tabular}{|l|l|l|l|}
\hline Levels & $\begin{array}{l}\text { Cutting speed } \\
(\mathrm{RPM})\end{array}$ & $\begin{array}{l}\text { Feed rate } \\
(\mathrm{mm} / \mathrm{rev})\end{array}$ & $\begin{array}{l}\text { Depth of cut } \\
(\mathrm{mm})\end{array}$ \\
\hline 1 & 420 & 0.05 & 0.50 \\
\hline
\end{tabular}




\begin{tabular}{|l|l|l|l|}
\hline 2 & 420 & 0.11 & 0.75 \\
\hline 3 & 420 & 0.22 & 1.00 \\
\hline 4 & 710 & 0.05 & 0.75 \\
\hline 5 & 710 & 0.11 & 1.00 \\
\hline 6 & 710 & 0.22 & 0.50 \\
\hline 7 & 1200 & 0.05 & 1.00 \\
\hline 8 & 1200 & 0.11 & 0.50 \\
\hline 9 & 1200 & 0.22 & 0.75 \\
\hline
\end{tabular}

The experimental trials were carried out under dry cutting condition using tungsten carbide insert of $0.40 \mathrm{~mm}$ corner nose radius with $20^{\circ}$ rake angle. Figure 1 shows the experimental set for the present work.

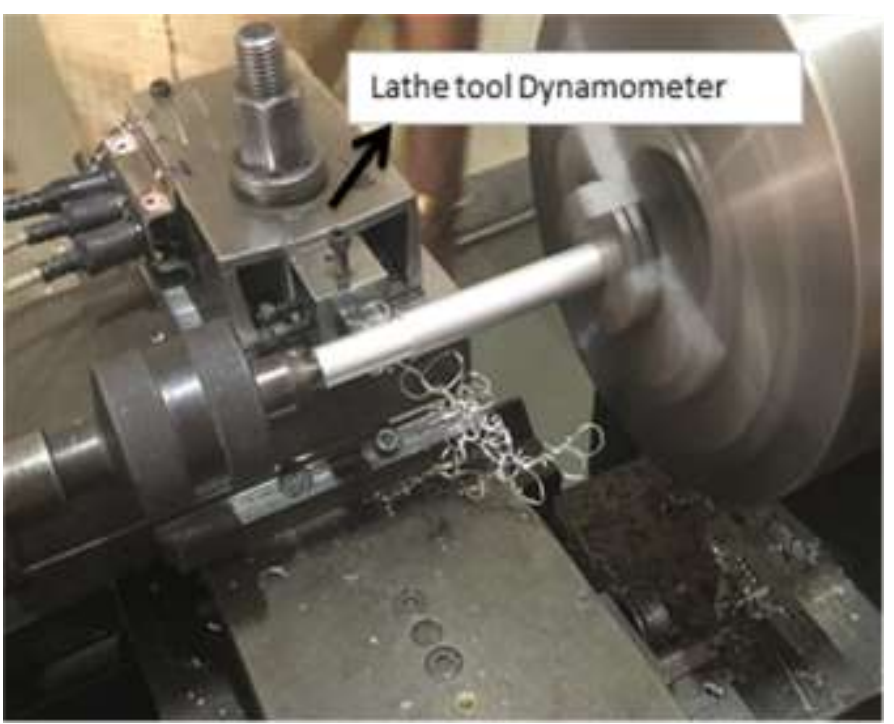

Figure 1: Experimental Setup

Each experimental trial was carried out for machining $25 \mathrm{~mm}$ length of $\mathrm{Al} 6081$ specimen and recording the corresponding cutting force from the lathe tool dynamometer. Later, after machining, the surface roughness of the machined portion of the specimen was measured using Mitutoyo SJ-201 surface roughness measuring instrument. Frictional forces for every trial were computed using the relations derived from Merchant circle diagram. Table 3 shows the measured cutting forces, calculated frictional forces, and surface roughness against each trial. The effect of process parameters on the output parameters were analyzed further by using ANOVA tool from Statistica software.

Calculation of frictional force from the equation derived from Merchant circle diagram for trial 1 is as follows.

$\mathrm{F}=\mathrm{F}_{\mathrm{c}} \sin \alpha+\mathrm{F}_{\mathrm{v}} \cos \alpha \ldots \ldots \ldots \ldots$ (Equation derived from the Merchant circle diagram [12])

Where,

$\mathrm{F}=$ Frictional force in Newton

$F_{c}=$ Cutting force in Newton
$F_{v}=$ Feed force in Newton

$\alpha=$ Rake angle of the insert in Degrees

$\mathrm{F}=29.43^{*} \sin \left(20^{\circ}\right)+9.81 * \cos \left(20^{\circ}\right)$

$\mathrm{F}=19.28 \mathrm{~N}$

Similarly frictional force is calculated for all the trials.

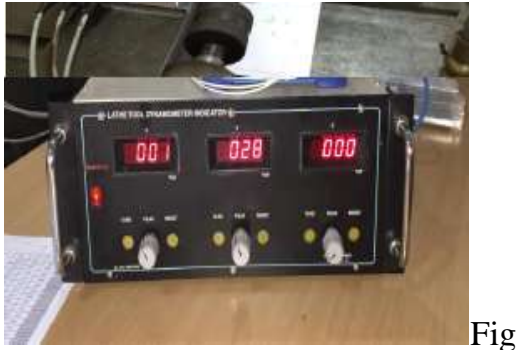

ure 2: Forces measurement

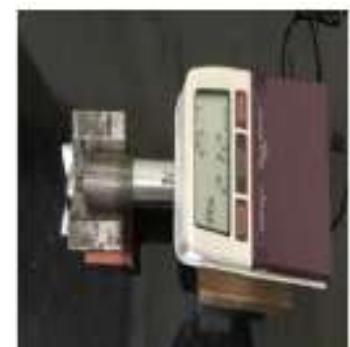

Figure 3 : Surface roughness measurement
Table 3: Measured and calculated output values

\begin{tabular}{|l|l|l|l|l|l|}
\hline Trials & $\begin{array}{l}\text { Cutting } \\
\text { force } \\
(\mathrm{N})\end{array}$ & $\begin{array}{l}\text { Feed } \\
\text { force } \\
(\mathrm{N})\end{array}$ & $\begin{array}{l}\text { Thrust } \\
\text { force } \\
(\mathrm{N})\end{array}$ & $\begin{array}{l}\text { Frictional } \\
\text { force }(\mathrm{N})\end{array}$ & $\begin{array}{l}\text { Surface } \\
\text { roughness } \\
(\mu \mathrm{m})\end{array}$ \\
\hline 1 & 29.43 & 9.81 & 9.81 & 19.28 & 1.230 \\
\hline 2 & 98.10 & 29.43 & 19.62 & 61.19 & 2.290 \\
\hline 3 & 294.3 & 39.24 & 29.43 & 137.48 & 8.030 \\
\hline 4 & 98.10 & 58.86 & 9.81 & 88.85 & 1.277 \\
\hline 5 & 88.29 & 68.67 & 29.43 & 94.72 & 2.307 \\
\hline 6 & 88.29 & 58.86 & 29.43 & 85.50 & 4.423 \\
\hline 7 & 117.72 & 88.29 & 9.81 & 123.21 & 2.120 \\
\hline 8 & 127.53 & 88.29 & 9.81 & 126.57 & 1.953 \\
\hline 9 & 196.2 & 78.48 & 29.43 & 140.82 & 4.750 \\
\hline
\end{tabular}

\section{RESULTS AND DISCUSSION}

The relationship between the input and output parameters is developed using ANOVA tool which is an inbuilt application of Statistica software. The experimental data was entered into this computing tool.Tthis data was further submitted for the analysis by defining the input data as independent variable and output data as dependent variable. In the ANOVA results, Ftest values were used at $95 \%$ confidence level to decide the significance factor affecting the process and percentage of contribution. As per ANOVA the least value of ' $p$ ' and the maximum value of ' $\mathrm{f}$ ' indicate the influence of machining parameter on the output.

The results obtained from the ANOVA tool for frictional force and surface roughness is tabulated in table 4 and the tabulated values provide the information on influence of process parameters on frictional force and surface roughness. It is clear from the ANOVA results that, spindle speed influences the frictional force and feed rate influences the surface roughness. The same influence has been demonstrated in the figure 4 and figure 5 graphically. 
Table 4: ANOVA results

\begin{tabular}{|c|c|c|c|c|c|}
\hline Effect & $\begin{array}{l}\text { Sum } \\
\text { of } \\
\text { Square } \\
\text { s (SS) }\end{array}$ & $\begin{array}{l}\text { Degre } \\
\mathrm{e} \quad \text { of } \\
\text { Freed } \\
\text { om } \\
\text { (DOF) }\end{array}$ & $\begin{array}{l}\text { Mean } \\
\text { of } \\
\text { Square } \\
\text { (MS) }\end{array}$ & $\begin{array}{l}\text { Frequen } \\
\text { cy }(\mathrm{F})\end{array}$ & $\begin{array}{l}\text { Percentag } \\
\mathrm{e} \text { of } \\
\text { Contribut } \\
\text { ion }(\mathrm{p})\end{array}$ \\
\hline \multicolumn{6}{|c|}{ Frictional Force } \\
\hline $\begin{array}{l}\text { Spindl } \\
\text { e } \\
\text { speed }\end{array}$ & $\begin{array}{l}5243.4 \\
24\end{array}$ & 2 & $\begin{array}{l}2621.7 \\
12\end{array}$ & $\begin{array}{l}2.81970 \\
4\end{array}$ & 0.261800 \\
\hline $\begin{array}{l}\text { Feed } \\
\text { rate }\end{array}$ & $\begin{array}{l}2974.8 \\
77\end{array}$ & 2 & $\begin{array}{l}1487.4 \\
38\end{array}$ & $\begin{array}{l}1.59977 \\
0\end{array}$ & 0.384649 \\
\hline $\begin{array}{l}\text { Depth } \\
\text { of cut }\end{array}$ & $\begin{array}{l}2566.5 \\
58\end{array}$ & 2 & $\begin{array}{l}1283.2 \\
79\end{array}$ & $\begin{array}{l}1.38019 \\
2\end{array}$ & 0.420134 \\
\hline $\begin{array}{l}\text { Resid } \\
\text { ual }\end{array}$ & $\begin{array}{l}1859.5 \\
66\end{array}$ & 2 & $\begin{array}{l}929.78 \\
3\end{array}$ & & \\
\hline \multicolumn{6}{|c|}{ Surface Roughness } \\
\hline $\begin{array}{l}\text { Spindl } \\
\mathrm{e} \\
\text { speed }\end{array}$ & $\begin{array}{l}2.2950 \\
3\end{array}$ & 2 & $\begin{array}{l}1.1475 \\
1\end{array}$ & 1.37453 & 0.421137 \\
\hline $\begin{array}{l}\text { Feed } \\
\text { rate }\end{array}$ & $\begin{array}{l}30.593 \\
35\end{array}$ & 2 & $\begin{array}{l}15.296 \\
67\end{array}$ & $\begin{array}{l}18.3228 \\
1\end{array}$ & 0.051752 \\
\hline $\begin{array}{l}\text { Depth } \\
\text { of cut }\end{array}$ & $\begin{array}{l}4.5752 \\
6\end{array}$ & 2 & $\begin{array}{l}2.2876 \\
3\end{array}$ & 2.74019 & 0.267366 \\
\hline $\begin{array}{l}\text { Resid } \\
\text { ual }\end{array}$ & $\begin{array}{l}1.6696 \\
9\end{array}$ & 2 & $\begin{array}{l}0.8348 \\
4\end{array}$ & & \\
\hline
\end{tabular}

The graphical representation of effect of process parameters on frictional force and surface roughness are presented in figure 4 and figure 5 respectively. From figure 4, it is clear that the signal to noise ratio is more in case of spindle speed than for feed rate and depth of cut, hence confirming the influence of spindle speed on frictional force. It is also clear from the figure 4 that the optimal process parameter values for minimum frictional force are $710 \mathrm{RPM}, 0.11 \mathrm{~mm} / \mathrm{rev}$ and 0.75 $\mathrm{mm}$. From figure 5, it is clear that the signal to noise ratio is more in case of feed rate than for spindle speed and depth of cut, hence confirming the influence of feed rate on surface roughness. It is also clear from the figure 5 that the optimal process parameters values for minimum surface roughness are $1200 \mathrm{RPM}, 0.11 \mathrm{~mm} / \mathrm{rev}$ and $0.75 \mathrm{~mm}$.

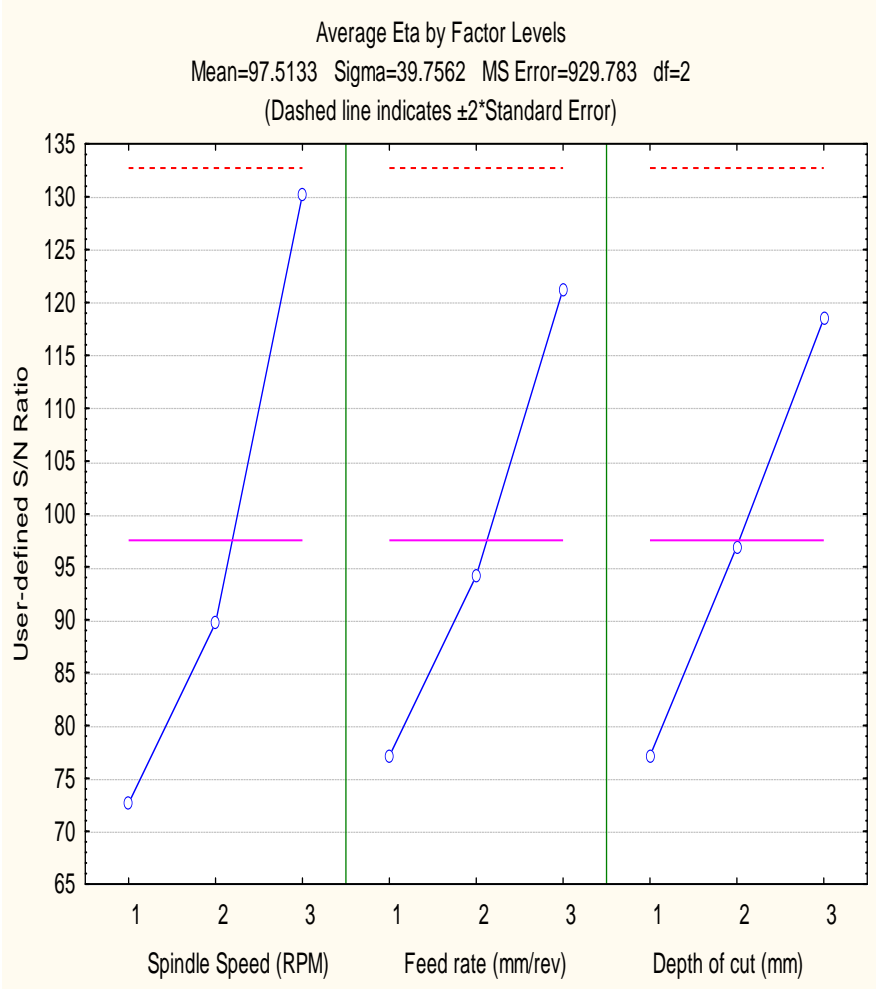

Figure 4: Graphical representation of process parameters on frictional force

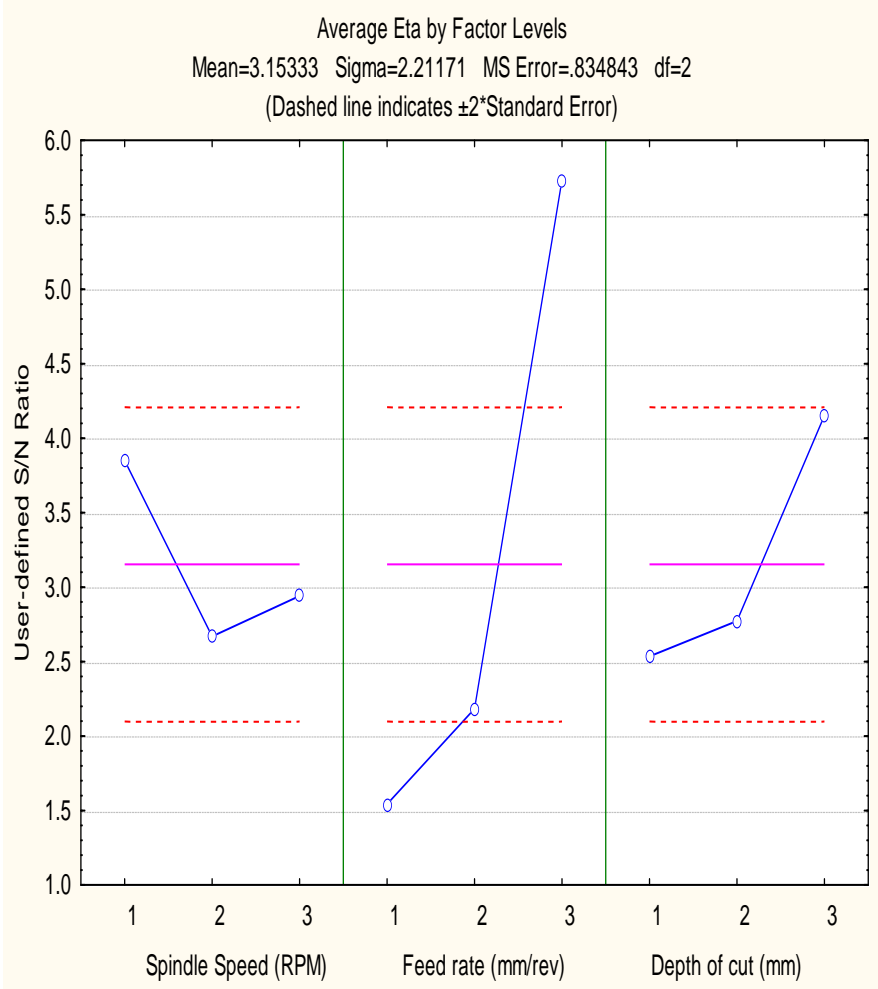

Figure 5: Graphical representation of process parameters on surface roughness. 


\section{CONCLUSIONS}

The experimental investigation describes the use of one of the cost effective deign of experimental technique, Taguchi's orthogonal array and data analysis technique, ANOVA in turning process to identify the influencing and optimal values of process parameters on frictional force and surface roughness. The experimental work was carried out on $\mathrm{Al} 6081$ specimens using $0.4 \mathrm{~mm}$ nose radius tungsten carbide insert tool with dry machining condition. The study reveals that the influencing process parameters as spindle speed for frictional force and feed rate for surface roughness. The study also reveals the optimal process parameters such as spindle speed, feed rate and depth of cut for minimum frictional force and surface roughness.

\section{REFERENCES}

[1]. Muhammad Munawar, Nadeem A, Mufti, and Hassan Iqbal, "Optimization of Surface Finish in Turning Operation by Considering the Machine Tool Vibration using Taguchi Method", Mehran University Research Journal of Engineering \& Technology, Volume 31, No. 1, January, 2012.

[2]. Satyanarayana Kosaraju, Venu Gopal Anne \& Bangaru Babu Popuri, "Taguchi Analysis on Cutting Forces and Temperature in Turning Titanium Ti-6Al-4V", International Journal of Mechanical and Industrial Engineering (IJMIE), ISSN No. 2231 -6477, Vol-1, Issue-4, 2012

[3]. Farhad Kolahan, Mohsen Manoochehri and Abbas Hosseini, "Simultaneous optimization of machining parameters and tool geometry specifications in turning operation of AISI 1045 steel", World Academy of Science, Engineering and Technology, 2011

[4]. Farhad Kolahan, Mohsen manoochehri , Abbas Hosseini, Application of Taguchi Method and ANOVA Analysis for Simultaneous Optimization of Machining Parameters and Tool Geometry in Turning, World Academy of Science, Engineering and Technology February 2011 ISSN:74 2011.

[5]. Zeelan Basha N, Selva Ganesh Kumar and Endalkachew Mosisa, Determining the Effect of Cutting Parameters on Surface Roughness Using Genetic Algorithm. Science, Technology and Arts Research Journal, Oct-Dec 2013, Vol. 2.

[6]. Vikas B. Magdum, Vinayak R. Naik.Evaluation and Optimization of Machining Parameter for turning of EN 8 steel. International Journal of Engineering Trends and Technology (IJETT), May 2013, Vol. 4. ISSN: 2231-5381.

[7]. Harish Kumar, Mohd. Abbas, Dr. Aas Mohammad, Hasan Zakir Jafri.Optimization of cutting parameters in CNC Turning. International Journal of Engineering Research and Applications (IJERA), May-Jun 2013, Vol. 3. ISSN: 2248-9622.
[8]. N.Kusuma, Megha Agrawal, P.V.Shashikumar, Investigation on the influence of cutting parameters on Machine tool Vibration \& Surface finish using MEMS Accelerometer in high precision CNC milling machine, 5th International \& 26th All India Manufacturing Technology, Design and Research Conference (AIMTDR 2014) December12th - 14th , 2014, IIT Guwahati, Assam, India

[9]. A Brief Introduction to Design of Experiments. Telford, Jacqueline K. 3, s.l. : Johns Hopkins APL Technical Digest, 2007, Vol. 27.

[10]. Srinivas Athrey, Dr Y.D.Venkatesh, Application Of Taguchi Method For Optimization Of Process Parameters In Improving The Surface

[11]. Roughness Of Lathe Facing Operation. International Refereed Journal of Engineering and Science (IRJES), November 2012, Vol. 1. 2319-1821.

[12]. S.P.Gupta, Statistical Methods, Volume 2, Chapter 5, ftest and analysis of variance, page number 1009 1020.

[13]. Mechanics of machining, Lesson 8 - Machining forces and Merchant's circle diagram, Version 2, ME, IIT, Kharagpur. 